\title{
The Effects of Colored Brain Communication and Brain Processing Interpretation on the Academic Performance of Students: A Literature Review
}

\author{
F. C. J. Chin, M. L. Ooi, and M. W. Yip
}

\begin{abstract}
The purpose of this study is to identify the relationship between communication and brain processing indicator and academic performance of students majoring in Engineering, Business, Science and Social Science at a higher learning institution. This paper presents a preliminary literature review in the field of effects of communication and brain processing interpretation. The preliminary literature review highlighted that the brain processing indicator, i.e. types of colored brain, may have an effect on the academic performance of the students at higher learning institutions. Based on the findings of the literature, a conceptual model has been developed. The paper concludes with a proposed conceptual model and hypotheses for the effect of communication and brain processing indicator on the academic performance of students, as well as the limitations of this study and the directions of future research.
\end{abstract}

Index Terms-Brain processing interpretation, color brain, communication, higher learning institutions, academic performance.

\section{INTRODUCTION}

Higher learning institutions have faced many challenges in order to prepare graduates to be competent and employable in the industries or corporate sectors. Most corporations in Malaysia will require the graduates to be able to perform in the workplace immediately right after they are employed (Ooi, Goh \& Beh, 2007) [1]. The employers, apart from looking at the academic results of job applicants, are also evaluating the applicants' personality, leadership characteristics and other criteria. As such, personality characteristics have become one of the areas for many researchers to research on the relationship between personality and academic performance.

This can be proven by looking at a number of inventories on the various aspects of learners, such as personality, behaviour or cognitive level, which have been created and employed by different researchers to understand and explain how we learn best. Over the past three decades, numerous researches have been conducted to study the impact of these inventories on the learners' academic performance. Among

Manuscript received March 29, 2015; revised August 11, 2015.

F. C. J. Chin is with the Centre for National Building and Languages, Tunku Abdul Rahman University College, Malaysia (e-mail: chinfc@acd.tarc.edu.my).

M. L. Ooi is with the Faculty of Accounting, Finance and Business, Tunku Abdul Rahman University College, Malaysia (e-mail: ooiml@acd.tarc.edu.my).

M. W. Yip is with the Faculty of Engineering and Built Environment, Tunku Abdul Rahman University College, Malaysia (e-mail: yipmw@acd.tarc.edu.my). the many inventories available is Carmazzi's Colored Brain Communication Inventory which was developed by Arthur F. Carmazzi (2004) [2].

According to Carmazzi (2008), all of us process information obtained from our environment differently; our communication style is based on how we think, and our thinking style will be based on our brain genetic processor [3] $\mathrm{He}$ discovered that our genetic brain processor is able determine our character and communication style. Therefore, he developed his brain processing indicator that comprises four different brain colours, i.e. the red brain, the green brain, the purple brain and the blue brain, which are used to describe the different characteristics of our genetic processing and mental flexibility or communication style. He mentioned that people with different brain colours may have a direct impact on their communication with others such as miscommunications and misunderstandings, which in turn may affect their working relationship with other people and, most importantly, their work performance. As such, by understanding our brain colors and the distinctive communication characteristics, we will be able to develop appropriate personal communication strategies to capitalise on our strengths, as well as leveraging on the strengths of others to overcome our shortcomings.

However, no insight has yet to emerge on the effects of the different brain communication processes on tertiary students' academic performance in Malaysia, as well as other countries or parts of the world. Therefore, the purpose of this study is to explore the relationship between communication and brain processing indicator and academic performance of students majoring in four different fields of studies, i.e. Engineering, Business, Science and Social Science, at a higher learning institution in Malaysia. This paper provides the literature review mainly based on the literature of brain processing interpretation with the intention of identifying the effects of communication and brain processing indicator on the academic performance of the students at higher learning institutions.

\section{LITERATURE REVIEW}

According to Segal and Horne's personality dynamic (1997), some people function as 'mentally centred' system, some are 'emotionally centred' and others are 'physically centred' [4]. They studied over 80,000 people, including a group of children who were observed over 25 years.

Meanwhile, Hoschl and Kozeny (1997). who applied Cloninger's Tridimensional Personality Questionnaire to 
predict the academic performance of medical students in the first three years, found that personality traits may be a significant predictor of students' academic success during their first three years of study in a higher institution of education [5].

Horak and Du Toit (2002), on the other hand, applied the Herrmann Brain Dominance instrument to carry to out a study on the thinking styles and academic performance of first year civil engineering students, as well as on the lecturing staff [6]. The results confirmed a predominantly left brain bias among students and lecturing staff. They also found that students' academic records were correlated with their thinking preferences and the results confirmed that right brain dominant students tend to perform academically below average and less well than left brain dominant students.

As for Carmazzi, whose inventory is the main focus and instrument of this research, he studied the Herrmann's clinical study (1972), Segal \& Horne's observatory study (1979) and Cloninger's pathological study (1994) and found some similarities as well as discrepancies in these studies in order to get a more factual representation. He assumed that everybody cannot be right if they come up with different conclusions. As such, he has identified four detailed primary genetic brain communication processes which were correlated with Segal \& Horne, Hermann and Cloninger's studies to develop a profiling instrument known as the Colored Brain Communication Inventory (Carmazzi, 2008b) [7]. He hypothesises that people are distinguished from others by their own specific way of processing the world around them, processing information, learning, solving problems, communicating and relating to others.

\section{A. Brain Processing Indicators}

According to Carmazzi (2008), his brain processing indicator consists of the following four different colored brains and their characteristics [1]:

\section{1) The green brain}

Those with a green brain are characterised by the following:

1) They process their environment as a summary of the overall situation, and they see the 'big picture' of things they are involved in.

2) Their thinking is in non-linear random chunks where nothing is connected. As such, they are able to adopt multiple ways of approaching a task.

3) Their action sequence collects a little information, immediately takes action, and processes information and actions.

4) They like to interact with others in exchanging ideas to help them to assist them in making sense of their direction.

5) They are able to work well with others as well as independently. They can collaborate with others easily to produce creative approaches to deal with an issue and they will have a big picture outcome in mind when they start a project.

6) They will tackle a problem immediately.

7) They will usually ask many questions to attempt to understand things objectively.

\section{2) The red brain}

Those with a red brain are characterised by the following:

1) They have a clear sense of purpose and direction because of their linear cross referencing nature.

2) They tend to analyse situations and deal with issues, one at a time. Therefore, they can be very clear and precise in their communication with others.

3) They are detailed-oriented. They enjoy gathering information, process and shape the information obtained in a structured way.

4) They are able to process information and facts logically. As such, they can be very objective.

5) They are usually not very expressive and are able to remain calm despite being in a stressful situation.

6) They also process information from a long term perspective and often look in the future.

7) They always like to deliberate on all the issues and solutions thoroughly before making any decision, and they tend to work alone.

\section{3) The purple brain}

Those with a purple brain are characterised by the following:

1) They value information a lot and thrive on it.

2) They tend to take in a lot of information before they make any decision or take any action.

3) They will collect as much information as possible and connect the information obtained with time, tasks, people, etc. on a framework.

4) They need details information from a different perspective to enable them to make a good decision.

5) As they are able to accumulate information and encode it for future use, they often have a sense of individual identity.

6) Their way of learning is to absorb a significant amount of information and have ample time to digest the information obtained in order to understand the context clearly and communicate it to others.

7) They are usually more inclined to follow rules due to their orderly nature.

\section{4) The blue brain}

Those with a blue brain are characterised by the following:

1) They are more intuitive in nature.

2) They are sensitive to their surroundings and the feelings of others. Therefore, they can be emphatic.

3) They are flexible and capable of playing multiple roles.

4) They are able to multi-task quite well and are organised.

5) They can be sensitive to others' feelings. At the same time, they may find it hard to differentiate their own feelings from others.

6) Relationship and people are vital in their life. They prefer to develop a personal connection with the people they work or communicate with.

7) They are able to communicate at a deeper and personal level with others because of their expressiveness and intuition.

\section{B. Academic Performance}

According to Carmazzi (1999), by identifying the fundamental patterns in the way the brain genetically processes the world around us, students will be able to perform well in their studies by fully optimising their strengths to achieve good academic performance [8]. Therefore, awareness of brain communication processes will 
give the means to them to maximise their potential or capacity and act intelligently in their studies, which will in turn lead to the good academic performance. When students understand their own color brain as well as others', they will have mutual understanding between themselves, hence reducing the communication gap between them and indirectly increasing their performance.

\section{Conceptual Model}

The literature review above indicates that different people has different brain processing indicator, i.e. colored brain which has different characteristics and communication styles. Based on the literature review, the research hypotheses of the study are developed as follows. The conceptual model is shown in Fig. 1.

\section{Hypotheses Development}

The research hypotheses of the study are as follows:

As presented in the literature review, people with a purple brain like to absorb a lot of information and require detailed information to make a good decision or take action. They like to follow rules and regulations. As such, it is deduced that science and engineering students are deemed to be purple brain people based on the purple brain characteristics. Therefore, the first hypothesis is as follows:

$\mathrm{H}_{1}$ : There is a significant relationship between science and engineering students' purple-colored brain communication processes and their academic performance.

As highlighted in the literature review, people with a green brain are able to see the big picture of things and their thinking is in non-linear. They tend to talk a lot but are able to work well with people generally. As such, it is deduced that marketing students are deemed to be green brain people based on the green brain characteristics. Therefore, the second hypothesis is as follows:

$\mathrm{H}_{2}$ : There is a significant relationship between marketing students' green-colored brain communication processes and their academic performance.

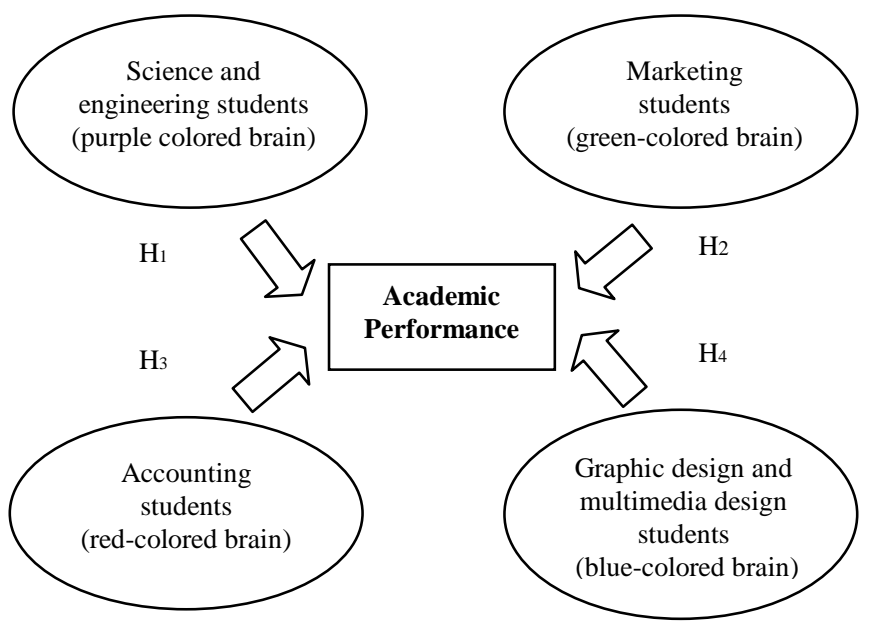

Fig. 1. Conceptual model.

As stated in the literature review, people with a red brain have a clear direction because of their linear cross referencing nature. They tend to analyse situation constantly, clearly and precisely. They always think through all the issues and solutions before making any decision or taking any action. As such, it is deduced that accounting students are deemed to be red brain people based on the red brain characteristics. Therefore, the third hypothesis is as follows:

$\mathrm{H}_{3}$ : There is a significant relationship between accounting students' red-colored brain communication processes and their academic performance.

As reported in the literature review, people with a blue brain are flexible and their sensitivity towards others gives them the ability to be emphatic. To them, relationship and people are an integral part of their life. As such, it is deduced that graphic design and multimedia design students are deemed to be blue brain people based on the blue brain characteristics. Therefore, the fourth and final hypothesis is as follows:

$\mathrm{H}_{4}$ : There is a significant relationship between graphic design and multimedia design students' blue-colored brain communication processes and their academic performance.

\section{CONCLUSION}

Based on the literature review presented, a conceptual model has been developed as presented in Fig. 1. The model explains that there is a correlation between the communication and brain processing indicator and academic performance of the students majoring in Engineering, Business, Science and Social Science at higher learning institutions. The proposed conceptual model may indicate some limitations in term of validity. As such, further empirical research is required in the form of survey research and employing statistical analysis to validate the conceptual model. The next phase of the study will be the administration of the Colored Brain Communication Inventory on 400 students from Accounting, Marketing, Science, Engineering, Graphic Design and Multimedia Design programmes of an institution of higher learning in Malaysia. Thereafter, data obtained from the instrument will be analysed using the SPSS statistical analysis.

\section{ACKNOWLEDGMENT}

The authors would like to express their sincere appreciation to Tunku Abdul Rahman University College and Ms Lily Lau, Directive Communication Accredited Master Trainer, for supporting this research.

\section{REFERENCES}

[1] K. K. Ooi, C. H. Goh, and Y. H. Beh, "Personality type and academic performance of undergraduates majoring in engineering and accounting," in Proc. the 1st International Conference on Teaching and Learning (ICTL), Putrajaya, Malaysia, 2007.

[2] F. A. Carmazzi, "Colored brain communication card," Directive Communication International, 2004.

[3] F. A. Carmazzi. (2008). The colored brain communication inventory. [Online]. Available: www.directive communication

[4] S. Seagal and H. Horne, Human Dynamics: A New Framework for Understanding People and Realising the Potential in Our Organizations, Cambridge: Pegasus Communications, 1997.

[5] C. Hoschl and J. Kozeny, "Predicting academic performance of medical students: The first three years," The American Journal of Psychiatry, vol. 154, no. 6, pp. 87-92, 1997.

[6] E. Horak and J. W. Du Toit, "A study of the thinking styles and academic performance of civil engineering students," Journal of the South African Institution of Civil Engineering, vol. 44, no. 3, pp. 18-24, 1999.

[7] F. A. Carmazzi, "Colored brain communication inventory," Directive Communication International, 2008 
[8] F. A. Carmazzi, "The colored brain communication field manual: Practical applications of directive communication psychology and the colored brain to work, leadership, business and relationship," Directive Communication International, 1999.

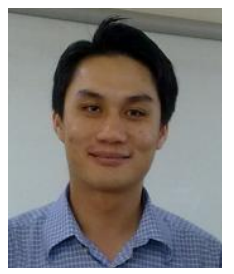

F. C. J. Chin possesses a bachelor in education (hons) teaching English as a second language (TESL) from University of Exeter, UK in 2001 and a master in arts English (specialising in English for specific purposes) from Universiti Putra Malaysia, Malaysia in 2004. He is presently reading for his $\mathrm{PhD}$ in education at Open University Malaysia, Malaysia. He is currently the head, Division of English and Foreign Languages, Centre for Nation Building and Languages at Tunku Abdul Rahman University College, Malaysia.

He possesses vast experience in teaching English and has authored and published, to date, 15 English textbooks and workbooks for schools, colleges and universities in Malaysia. He has also published two papers in the field of science education.

Mr Chin was previously involved in a three-year international research project funded by the European Union Science in Society Framework 7 Programme on Science Education for Diversity. The research project involves six reputable institutions of higher learning from Malaysia, the Netherlands, India, Lebanon, the UK and Turkey.

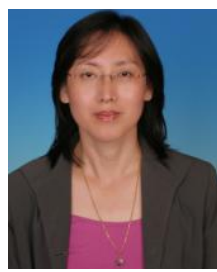

M. L. Ooi graduated with a diploma in commerce (business management) in 1986. She also obtained the institute chartered secretaries and administrators qualification in 1986. She received her master of science in property investment from City University, London, U.K. in 1994.

She is currently a senior lecturer in the Department of Marketing in the Faculty of Finance, Accountancy and Business at Tunku Abdul Rahman University College. She teaches marketing at diploma and undergraduate level at Tunku Abdul Rahman University College.

Ms Ooi has 15 years of working experience in the financial sector. Professionally, she is an associate member with the Malaysian Institute of Chartered Secretaries and Administrators, an associate member of Malaysian Institute of Management and a certified member with Financial Planning Association of Malaysia.

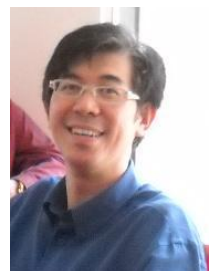

M. W. Yip graduated with a diploma in materials engineering from Tunku Abdul Rahman College, Malaysia in 1997 and a MSc in manufacturing systems engineering from University of Warwick, U.K. in 1998. In 2008, he was awarded an engineering doctorate in engineering business management (specialising in knowledge management) from Business Advanced Technology Centre, Universiti Teknologi Malaysia, Malaysia.

$\mathrm{He}$ is currently the associate dean, Department of Mechanical Engineering, Faculty of Engineering and Built Environment at Tunku Abdul Rahman University College, Malaysia. He is also a certified knowledge management facilitator and practitioner, a certified TRIZ practitioner, a senior member of International Association of Computer Science and Information (IACSIT) and a member of Malaysia TRIZ Innovation Association. He has presented many papers in the field of engineering management especially in KM in many international conferences in China and Indonesia. He is also a reviewer and an Editorial Board Member for International Journals.

Dr Yip has a lot of experience in research. He has been given a grant by the Ministry of Higher Learning Institution to conduct a research in the implementation of KK in SME in Malaysia. 